\title{
Correction to: Adequate Multivitamin Supplementation after Roux-En-Y Gastric Bypass Results in a Decrease of National Health Care Costs: a Cost-Effectiveness Analysis
}

\author{
Jens Homan ${ }^{1} \cdot$ Wendy Schijns ${ }^{1} \cdot$ Ignace M. C. Janssen $^{1}$ • Frits J. Berends ${ }^{1} \cdot$ Edo O. Aarts ${ }^{1}$
}

Published online: 18 March 2019

(C) Springer Science+Business Media, LLC, part of Springer Nature 2019

\section{Correction to: Obesity Surgery}

https://doi.org/10.1007/s11695-019-03750-6

In the original article, there are some incorrect data in the "Results" section of the Abstract. The corrected "Results" section is as follows:

Results: In total, 10 (14\%) patients in the WLS Forte ${ }^{\circledR}$ group versus $23(30 \%)$ patients in the sMVS group developed a deficiency. The costs for the WLS Forte ${ }^{\circledR}$ supplement were $\mathbf{€ 3 0}$ versus $\mathbf{€ 2 1}$ for sMVS. Additional return visits and associated costs for medical staff were the largest costs, up to $\mathbf{3 4 \%}$ in the sMVS group. Total costs for supplementation with sMVS were $\boldsymbol{€ 3 0 6}$ versus $\boldsymbol{€ 2 1 6}$ for WLS Forte ${ }^{\circledR}$.

Publisher's Note Springer Nature remains neutral with regard to jurisdictional claims in published maps and institutional affiliations.

The online version of the original article can be found at https://oi.org/ 10.1007/s11695-019-03750-6

Jens Homan

jenshoman@hotmail.com

1 Department of Surgery, Rijnstate Hospital, Postal Number 1190, 6800 TA Arnhem, The Netherlands 